\title{
"A HORA DA EDUCAÇÃO SEXUAL": PRÁTICAS EDUCATIVAS DO SEXO, DA SAÚDE E DAS DOENÇAS EM CONSELHOS IMPRESSOS (PARAÍBA, DÉCADA DE 1930)
}

\author{
"The Time of Sexual Education": educational practices for sex, health \\ and diseases in printed councils (Paraíba, 1930s)
}

\section{Azemar dos Santos Soares Júnior* Rafael Nóbrega Araújo**}

\begin{abstract}
Resumo: O presente artigo analisa os discursos médico-pedagógicos publicados na imprensa paraibana pelo Círculo Brasileiro de Educação Sexual (CBES), escritos pelo médico e autoproclamado sexólogo, José de Albuquerque sobre educação sexual ao longo da década de 1930. A documentação produzida pelo CBES e publicada em jornais paraibanos, continha orientações para pais e professores a respeito de como tratar da educação sexual com crianças e jovens à luz dos problemas fisiológicos relacionados a sexualidade, bem como das doenças venéreas. Compreendemos que tais discursos se configuravam como práticas educativas a partir do momento que visavam incutir nos leitores daqueles jornais hábitos e pensamentos higiênicos pautados pelo saber médico a respeito do sexo e da sexualidade. Encontramos publicações feitas pelo CBES em dois periódicos paraibanos da época, a saber, o diário A União de João Pessoa e o semanário Estado Novo de Cajazeiras, ambos alinhados politicamente com os governos à nível estadual e federal. Partimos do pressuposto de que tais impressos concordavam com as ideias do dr. José de Albuquerque, contribuindo para a divulgação da sexologia em terras paraibanas. Metodologicamente, nos valemos das proposições de Michel Foucault (2012) a respeito da análise do discurso conceito para realizar nossas leituras e produzir interpretações, em um jogo de troca de sentidos entre o historiador e as suas fontes.
\end{abstract}

Palavras-chave: Educação sexual. Práticas Educativas. José de Albuquerque.

\begin{abstract}
This article analyzes the medical-pedagogical speeches published in the Paraiba press by the Brazilian Circle of Sexual Education (CBES), written by the self-proclaimed sexologist, José de Albuquerque about sexual education throughout the 1930s. The documentation produced by CBES is published In Paraiba newspapers, it contained guidelines for parents and teachers on how to address sexuality education with children and youth in the light of physiological problems related to sexuality as well as venereal disease. We understand that these speeches were configured as educational practices from the moment they aimed to instill in the readers of those newspapers hygienic habits and thoughts based on medical knowledge about sex and sexuality. We found publications made by CBES in two Paraiban journals of the time, namely the newspaper A União of João Pessoa and the weekly Estado Novo of Cajazeiras, both politically aligned with the

\footnotetext{
* Doutor em Educação. rofessor de Departamento de Práticas Educacionais e Currículo da Universidade Federal do Rio Grande do Norte. Professor do Progeama de Pós-Graduação em História da Universidade Federal de Campina Grande (PPGH/UFCG) e do Programa de Pós-Graduação em Educação da Universidade Federal do Rio Grande do Norte (PPGEd/UFRN). E-mail: azemarsoares@hotmail.com

** Graduado em História. Mestrando pelo Programa de Pós-Graduação em História da Universidade Federal de Campina Grande. E-mail: rafael.nobreg.araujo@gmail.com
} 
governments at the state and federal levels. We assumed that these forms agreed with the ideas of dr. José de Albuquerque, contributing to the dissemination of sexology in Paraíba lands. Methodologically, we use Michel Foucault's (2012) propositions regarding the analysis of concept discourse to perform our readings and produce interpretations, in a game of exchange of meanings between the historian and his sources.

Keywords: Sex Education. Educational practices. Jose de Albuquerque.

\section{Introdução}

"Pode-se afirmar sem receio de errar, que soou para o mundo, a hora da educação sexual". Com essa afirmação, abria-se a chamada sobre a educação sexual na edição de 23 de março de 1934 do jornal A União. Tratava-se de um texto remetido pelo Serviço Especial do Círculo Brasileiro de Educação Sexual e escrito pelo médico e autoproclamado sexólogo, José de Albuquerque, que consistia num aviso para a eclosão das ideias sobre a sexualidade como elemento central na sociedade, considerado pelo médico como um problema fundamental que se colocava para os brasileiros. O esculápio considerou que no Brasil não se deveria calar a respeito desse assunto e seguir o modelo dos países "cultos" do mundo. Ignorar a questão sexual seria não só prova de incultura por parte do Brasil, como sinal de estar arrastando o país e o seu povo para a retaguarda da civilização.

O médico carioca José de Albuquerque, foi líder e fundador de uma organização civil chamada de Círulo Brasileiro de Educação Sexual (CBES), criada no Rio de Janeiro, em 1933, a qual se destinava a promover a educação sexual. O sexólogo ganhou fama e renome nacionalmente, ficando notabilizado pela atividade de intensa propaganda desenvolvida ao longo da década de 1930 na capital federal. Os periódicos ${ }^{1}$ de divulgação científica fundados e dirigidos por Albuquerque tiveram uma tiragem de bastante vulto. Além da publicação de inúmeros livros, escreveu um semnúmero de artigos de caráter científico para divulgação, que eram distribuídos para todo o país em uma ampla rede de jornais e diários (CARRARA, 1996; CARRARA; CARVALHO, 2016).

Sérgio Carrara (1996), informou que em 1935 já faziam parte do circuito de divulgação do CBES aproximadamente setecentos jornais espacialmente distribuídos por todo o território nacional. Porém, segundo o próprio José de Albuquerque em sua autobiografia, organizada por Sérgio Carrara e Marcos Carvalho (2016) e publicada pela Editora da Fiocruz, a adesão de jornais chegaria a cerca de oitocentos e cinquenta jornais. O médico encontrou um excelente aliado na União Brasileira de Imprensa, que

[...] com irradiação em todo país compreendendo salutares ideologias por que esta nova instituição se batia, entrou logo a remeter para os jornais a ela afiliados, que se elevam ao avultado número de trezentos, artigos e notícias, chamando a atenção da população de todo o nosso vastíssimo binterland para esta novel instituição e seu vastíssimo programa (A União, 14 jan. 1934. Grifo no original)2.

A diretoria do CBES, também dirigiu o apelo aos diretores de jornais brasileiros do interior

10 médico fundou e dirigiu o Jornal de Andrologia (1932), voltado para uma campanha que visava a institucionalização da andrologia enquanto uma especialidade médica e o Boletim de Educação Sexual (1933), articulado em torno da divulgação da educação sexual, que segundo o médico seria a maneira mais efetiva de se evitar, entre outros males, as doenças venéreas. Para mais informações a respeito dos periódicos fundados e mantidos pelo dr. José de Albuquerque e o Círculo Brasileiro de Educação Sexual ver Carrara (1996).

2 Por uma questão metodológica, optamos por manter a grafia original dos documentos transcritos ao longo do texto. 
do país. Havendo conseguido congregar diversos órgãos da imprensa, a cada uma dos quais eram "[...] remetidos quinzenalmente, artigos sobre educação sexual, que são publicados com regularidade pela maioria dos mesmos", a campanha pela educação sexual seria, segundo José de Albuquerque, "[...] uma irradiação sem precedente nos anais da nossa história” (A União, 14 jan. 1934).

Conforme consta no livro Quatro letras, cinco lustros (1958), escrito pelo médico-sexólogo, e reproduzido de maneira fac-similar na coletânea organizada por Carrara e Carvalho (2016), no estado da Paraíba os jornais que constituíam o circuito do CBES eram os seguintes: Commercio da Paraíba, de João Pessoa; A Fôlha, de Itabaiana, O Tempo, de Esperança; O Norte, de João Pessoa; $A$ União, de João Pessoa; O Rebate, de Campina Grande; O Libertador, de João Pessoa; A Ordem, de Campina Grande (ALBUQUERQUE, 1958, p. 65). Acrescentaríamos ainda mais um jornal, que não consta na lista do próprio sexólogo, mas que em nossa pesquisa nos deparamos com publicações feitas pelo CBES em suas páginas, trata-se do semanário Estado Novo, de Cajazeiras.

José de Albuquerque se dedicou a uma intensa propaganda em prol da educação sexual, que seria para ele uma “[...] verdadeira panaceia para a solução não apenas do "problema venéreo", mas também da desarmonia conjugal, dos crimes sexuais, das perversões sexuais, das proles "taradas" e doentes, do abastardamento da raça, do charlatanismo" (CARRARA; CARVALHO, 2016, p. 14-15). O cerne do discurso do médico, que deslocou a discussão dos males venéreos para a própria sexualidade, e que foi repetida até a exaustão em seus artigos, livros e conferências, era a noção de que a "sexualidade não é imoralidade", muito embora, reconhecesse que a função sexual, como qualquer outra, poderia ser "imoralizada" (CARRARA; CARVALHO, 2016).

Nosso objetivo nesse artigo é analisar os discursos médico-pedagógicos publicados na imprensa paraibana pelo Círculo Brasileiro de Educação Sexual, de autoria do dr. José de Albuquerque, que continham informações referentes a conselhos de educação sexual. Foram artigos publicados em periódicos paraibanos desde 1933 até pelo menos 1941. Eram dirigidos para a população em geral, de modo que tais discursos pudessem instruir o maior número de pessoas possível, mas enfatizavam especificamente a função de pais e professores em orientar desde cedo crianças e jovens quanto a reprodução e a sexualidade humana, de modo a promover a profilaxia da sífilis e doenças venéreas através da intensa campanha de educação sexual.

Marcados pelo influxo de interesses, compromissos e paixões, como ponderou Tânia Regina de Luca (2008), os periódicos cristalizaram imagens subjetivas e, o mais das vezes, parciais sobre o cotidiano que noticiavam. As historiadoras Ana Luiza Martins e Tânia Regina de Luca (2008), argumentaram que a imprensa é “[...] a um só tempo, objeto e sujeito da história [...], mas também é veículo para a reconstrução do passado" (MARTINS; LUCA, 2008, p. 8). Ora, os impressos que circularam nas primeiras décadas do século XX testemunharam e registraram o crescente interesse a respeito da discussão em torno da educação sexual que marcou a década de 1930.

Em vista da disseminação da sífilis e outras doenças venéreas no país, ganhou relevo a ênfase na questão sexual como medida saneadora e profilática na luta antivenérea. O debate em torno dessa questão deslocou o problema da sífilis do campo da dermato-sifilografia para o âmbito da sexologia (CARRARA, 1996). Nesse sentido, os jornais que veicularam artigos do Círculo Brasileiro de Educação Sexual não apenas registraram e informaram o que aconteceu, mas também produziram, de certo modo, os acontecimentos que noticiavam, ou melhor dizendo, os discursos médico-pedagógicos que divulgavam, uma vez que, dessa forma, atuava na conformação de corpos e mentes, na formação do imaginário individual e coletivo a respeito da relevância da educação sexual para combater a sífilis e as doenças venéreas.

Dentre os jornais paraibanos que faziam parte do circuito do CBES, alguns como os jornais 
o Commercio da Paraíba, de João Pessoa; O Tempo, de Esperança; O Libertador, de João Pessoa; A Ordem, de Campina Grande, não encontramos qualquer registro nos arquivos públicos do estado da Paraíba. Outros, porém, como o jornal $A$ Fôlha de Itabaiana e O Rebate de Campina Grande, nos números esparsos e raros que encontramos, respectivamente, na Biblioteca de Obras Raras Átila de Almeida da Universidade Estadual da Paraíba e no Museu Histórico de Campina Grande, não verificamos nenhum artigo publicado pelo CBES. Contudo, o jornal $A$ União publicou uma enorme quantidade de artigos do dr. José de Albuquerque e também o semanário Estado Novo continha algumas publicações referentes a educação sexual remetidas pelo CBES. Selecionamos, portanto, artigos publicados nesses dois periódicos para análise. Com isso, procuramos demonstrar a circulação dos discursos do dr. José de Albuquerque sobre educação sexual com a maior abrangência geográfica que nos foi possível pela disponibilidade das fontes na Paraíba.

O jornal A União foi fundado por Álvaro Machado, Presidente da Província da Paraíba, em 1893, seu principal objetivo era o de “[...] ser o porta-voz do Partido Republicano e apoiar a gestão do seu fundador” (ARAÚJO, 1986, p. 41). Desde a sua fundação, este periódico era editado nas máquinas da Imprensa Oficial do Estado da Paraíba e esteve marcado pela sua posição editorial alinhada a situação governista. Por seu turno, o jornal semanário Estado Novo, foi fundado em 1939, órgão político e noticioso que tinha por objetivo, como o próprio nome sugere, "[...] a defesa dos ideais do regime ditatorial estadonovista, chefiado pelo Grande Presidente Getúlio Vargas" (SOUZA, 1981, p. 189). Ambos os periódicos se situavam como alinhados às perspectivas governistas. Advogamos da hipótese de que se os referidos jornais publicaram e divulgaram as ideias do dr. José de Albuquerque sobre educação sexual, havia, no mínimo, um alinhamento entre as ideias da linha editorial de ambos os periódicos com o projeto propagado pelo Círculo Brasileiro de Educação Sexual.

Para analisar os discursos sobre educação sexual publicados em periódicos que circularam na Paraíba na década de 1930, partimos de uma análise do discurso a partir das colocações de Michel Foucault (2012), para quem os enunciados discursivos são resultado das relações de poder que o produziram. Compreendemos com este autor, o discurso como uma gama de enunciados ao mesmo tempo controlado e organizado em conformidade com aquilo que era possível ser dito a respeito de uma coisa em determinado momento histórico. A questão sexual ganhou ampla relevância e notoriedade no contexto da década de 1930, possibilitando ao dr. José de Albuquerque e os periódicos a ele ligados produzirem discursos referentes ao sexo e a sexualidade.

Em nosso exercício metodológico, realizamos um jogo de escritura, de leitura e de troca. Ao nos depararmos com os discursos escritos pelo CBES e publicados na imprensa paraibana, realizamos nossas primeiras leituras que culminaram com a troca de sentidos a partir do diálogo estabelecido entre aquilo que lemos nas fontes e o que compreendemos. Nesse momento, o historiador realiza o movimento de troca. Tomamos os sentidos das fontes, para construir outros sentidos a partir de nossas leituras.

O artigo se estrutura a partir de três momentos: o primeiro problematiza o discurso do dr. José de Albuquerque a partir do que ele compreendia como educação sexual e do seu objetivo com um projeto de propaganda em torno da "questão sexual"; em seguida, partimos para uma reflexão em torno das implicações da educação sexual para no âmbito específico da luta antivenérea e, por fim, analisamos os conselhos médico-pedagógicos sobre educação sexual para pais e professores. 


\section{"Sexualidade não é immoralidade": a propaganda de educação sexual}

$\mathrm{Na}$ secção do diário $A$ União dedicada à educação sexual, o dr. José de Albuquerque se queixava, no seu primeiro artigo publicado neste diário paraibano, de que a palavra "sexual" estava tão deturpada no país “[...] quanto a sua verdadeira significação, que há até quem tenha vergonha de a pronunciar" (A União, 20 set. 1933). Para o médico, em decorrência da "falsa moral de nosso povo", a educação sexual ainda não havia conseguido "entrar em nosso país no domínio das realizações práticas" (A União, 20 set. 1933).

Devido a esse falso conceito, falar de educação sexual era "assumpto vedado, prohibido mesmo". Um tema tabu. O indivíduo que se atravessasse a tratar dele, receberia "[...] a pecha de licenciosos e immoraes" (A União, 05 jan. 1935). Mas para José de Albuquerque, "Sexualidade não é imoralidade". A ideia central do discurso do "sexólogo" era a de que a sexualidade não era sinônimo de imoralidade, muito embora admitisse, que como qualquer outra, a função sexual também poderia ser imoralizada, "ao se transformar em instrumento exclusivo de prazer" (CARRARA, 1996, p. 259). José de Albuquerque argumentava que nenhuma “[...] manifestação no organismo humano é immoral, porque todas obedecem ao imperativo categórico das leis, das leis biológicas pelo que cumprem ser devidamente conhecidas para terem sido respeitadas" ( $A$ União, 05 jan. 1935).

Para o médico, a função sexual nada tinha de imoral. Só se serviriam dela com fins imorais, aqueles indivíduos que "[...] não receberam desde os primórdios da sua vida educação sexual conveniente” (A União, 05 jan. 1935). No entanto, apenas seria tornado possível tratar da educação sexual, se antes de tudo fosse preparado o terreno "[...] afastando o preconceito de que a sexualidade implica em imoralidade", pois sem retirar essa "[...] canga que o povo traz nos hombros, não se sentira ele à vontade, para cogitar da questão sexual” (A União, 11 out. 1933). Para José de Albuquerque,

Só depois de haverem compreendido, que o conhecimento dos assuntos relativos à vida sexual, é da mais absoluta necessidade, e que, não envolvem em si, nenhuma imoralidade, é que os indivíduos não só, aceitarão de bom grado, os ensinamentos que lhes pretendemos ministrar, como também permitirão que se cogite deste assunto com seus filhos, no seu lar e na escola (A União, 11 out. 1933).

Vencida a barreira da moralidade a educação sexual encontraria terreno livre para proliferar. Era preciso descontruir nos indivíduos a imagem de que os assuntos relacionados à vida sexual não implicavam em nenhuma imoralidade. Somente dessa forma, é que os indivíduos poderiam se ver abertos aos ensinamentos que o médico José de Albuquerque e o Círculo Brasileiro de Educação Sexual poderiam ministrar-lhes, para orientar corretamente os caminhos que deveriam singrar relativos ao seu sexo e, ainda mais, ao sexo da família e ao sexo dos filhos na escola. Em outro artigo o médico lamentava o preconceito dos pais e professores em relação a educação sexual no âmbito escolar:

E, a “educação sexual” como disciplina escolar? Não falemos nisso, pois algum diretor escolar, mais esclarecido, nos ouvindo, será capaz de querer anexar ao programa de ensino do curso, mais essa disciplina, e, aí dele, poderá ser forçado, no dia seguinte, a fechar definitivamente o estabelecimento, por não permitirem os pais dos alunos, que seus filhos tornem a atravessar os humbrais daquela casa, onde mandaram "puros" e querem devolver "impuros e corrompidos". [...] Assim sendo, em vez do ensinamento das questões sexuais, ser ministrado pelos pais 
e pelos mestres, vão as crianças "aprender" a principio, com os famulos da casa, que sempre se insinuam a "ensina-las", tais assuntos e depois nos prostíbulos e nos alcouces, onde, entre um baralho de cartas e um copo de vinho, surge uma anedota, um dito picante, uma alusão malsã, de fundo sexual, que os jovens ouvem com curiosidade e sofreguidão, aprendendo, por conseguinte, a ridicularizar a função sexual, e a servir das questões que a ela se prendem, como assunto de mofa e de chacota (A União, 20 set. 1933).

$\mathrm{Na}$ ocasião, o médico se queixava de que se por ventura numa escola, algum diretor "mais esclarecido" resolvesse acrescentar a educação sexual como disciplina escolar, incorria no risco de ter o estabelecimento fechado pela não permissão dos pais em tratar desse assunto, considerado pelo médico de suma importância, mas tido como "imoral" sob o ponto de vista dos pais e professores. $\mathrm{O}$ autor do texto culpava os pais e professores por não quererem que a escola tocasse no assunto e a escola não fazendo isso deixaria de cumprir, segundo o médico, um importante papel, pois permitiria com que os jovens, incautos e sem orientação, viessem a aprender de forma "errada", ou seja, sem o devido cuidado e controle higiênico, em ambientes considerados insalubres como bares e bordéis e, portanto, de acordo com José de Albuquerque, de forma imoral e deturpada.

A crítica feita ao "falso moralismo" dos pais das crianças e jovens encontrava fundamentação científica, quando o médico colocava supostos malefícios que o "pudor desarrazoado" de pais e mestres traziam para a mocidade. Lesando a importante função sexual, seriam alteradas as funções mentais, podendo, inclusive "[...] até modificar as características físicas do indivíduo", mas apenas o médico sexologista seria capaz de perceber e diagnosticar esses riscos, pois:

Os malefícios qual tal pudor desarrazoado de pais e mestres, tem trazido à mocidade, malefícios que repercutem sobre o resto da existência do homem, lesando-o na mais importante de suas funções naquela que, quando alterada é capaz não só de alterar profundamente as funções mentais, como até modificar as características físicas do indivíduo, ninguém os vê tão claramente como o médico sexologista, e, por conseguinte, ninguém melhor do que este, para clamar pela necessidade da educação sexual (A União, 20 set. 1933).

Para José de Albuquerque, era de fundamental importância que as pessoas, mas principalmente os jovens, tivessem clareza com referência ao sexo e a sexualidade, de modo a prevenir o desenvolvimento de disfunções e doenças provenientes da prática sexual. É importante frisar, conforme analisou Sérgio Carrara (2016, p. 17), que esse médico era contrário tanto ao excesso como a abstinência sexual, pois uma vez que compreendia o desejo sexual como uma necessidade orgânica primária, assumia o pressuposto de que a função sexual existia e que ela não poderia ser escamoteada, negada. Todavia, não se deveria abusá-la para não transgredir as leis biológicas.

É interessante notar o lugar que o médico coloca para si e a sua sexologia, buscando a legitimação do saber e de uma verdade científica. Michel Foucault (2012), nos ensina a perceber que todo discurso científico apresenta como pano de fundo um saber que conforma o que é possível enunciar sobre as coisas em um determinado momento histórico. A gênese e transformação dos discursos se dão conforme certas condições de possibilidade ao mesmo tempo organizada e controlada por um certo número de dispositivos, obedecendo as correspondências entre diferentes saberes e as relações de poder que permitem trazer à tona aquilo que é possível ser dito, reconhecido e legitimado, ou, ao contrário, que deve ser interdito, ocultado, excluído.

Nesse sentido, dentre os procedimentos que organizam internamente o discurso, a disciplina define aquilo que é requerido para a construção de novos enunciados sobre algo, definindo 
um domínio de objetos, um conjunto de proposições consideradas verdadeiras que conformam, controlam, enfim, organizam o que é possível ser dito sobre determinada coisa. O discurso do sexólogo se constituía, dessa forma, como um princípio a partir do qual seria possível emitir proposições verdadeiras sobre o sexo e a sexualidade. Arrolhando para si um novo campo de saber, isto é, esta nova disciplina que seria a sexologia, José de Albuquerque reclama o controle sobre o que é possível enunciar com referência ao sexo e suas funções, reconhecendo e legitimando o "médico sexologista" como o único indivíduo que seria capaz de "clamar pela necessidade da educação sexual”.

Assim, o conhecimento das questões que se prendiam à sexologia era "[...] requerido não só para a orientação da conduta da vida biológica do homem, como para a solução dos mais importantes problemas da sua vida social" (A União, 11 out. 1933). Ao sexólogo cabia o saber para orientar não só a vida biológica individual, mas da espécie, do conjunto de viventes. No entanto, reconhecia que naquele momento no Brasil - e nesse aspecto não difere muito da nossa contemporaneidade -, "[...] nada se poderá conseguir de útil, se não se modificar a mentalidade do povo nesse sentido, ou melhor, si o não ambientá-lo a essas ideias" (A União, 11 out. 1933). Considerava ainda prematuro cogitar a educação sexual da criança e do adolescente, porque a maioria dos pais se oporiam devido aos ditames de uma "moral caduca". Assim, o médico e o CBES, ao qual presidia, preparavam o terreno para que pudesse ser anunciada a hora da educação sexual.

Desse modo, o médico se empenhava em remeter artigos para os jornais de modo a ir, pouco a pouco, apresentando suas ideias e buscando sustentação para operar o seu plano de educação sexual. E questionava: Por que se deve estudar sexologia? Esse era o título de um outro artigo publicado em nove de novembro de 1933 no jornal A União. Nele, o médico tentou justificar biológica e socialmente a importância de conhecer as questões referentes ao sexo. Do ponto de vista biológico, ele sustentou a importância que a função sexual teria sobre as demais funções do organismo. Segundo José de Albuquerque, a função sexual atuava de maneira tão preponderante sobre o organismo, que se poderia mesmo afirmar que o predicado sexual envolvia todas as funções orgânicas. Para o sexólogo:

Antes da puberdade, e muitas vezes mesmo, depois da sua instalação, as perturbações da função sexual têm uma influência tão grande sobre o organismo, que chegaram até o ponto de lhe modificar as suas características morfológicas. Ainda mais as alterações da função endocrínica das glândulas sexuais, se fazem sentir de uma maneira tão intensa, alterando o funcionamento das outras glândulas endocrínicas e acarretando profundas modificações nas demais funções do organismo que não raramente, atingem até a esfera das funções mentais. A repercussão sexual sobre as funções mentais, é tão pronunciada, que se pode mesmo dizer, ser a sexualidade o alicerce da psicologia e da psiquiatria (A União, 09 nov. 1933).

De acordo com o discurso do dr. José de Albuquerque, as alterações ou perturbações da função sexual poderia modificar as características morfológicas do corpo. Em biologia, a morfologia estuda o organismo ou partes dele. Segundo o médico, a perturbação da função sexual teria, portanto, a capacidade de alterar inclusive a estrutura do corpo ou de seus órgãos e glândulas. No caso ilustrado pelo médico, tais disfunções morfológicas provocariam alterações na função endócrina das glândulas sexuais, isto é, dos testículos e dos ovários. Quais seriam estes desvios? O médico esclareceu em outro artigo:

As mulheres barbadas e os homens de pelle glabra; as mulheres de voz grossa e os homens de voz de falsete; as mulheres que gostam das empresas perigosas arriscadas, e os homens que se 
deleitam a fazer crochet; tudo isso é reflexo de uma atividade sexual imperfeita, deficiente, mal regulada (A União, 24 out. 1934).

Mulheres masculinizadas, homens afeminados. Todos os comportamentos desviantes daquilo que é considerado como "normal" do ponto de vista da sexualidade e os papéis de gênero atribuídos socialmente, seriam considerados uma anormalidade, disfunções sexuais cujas alterações seriam provocadas perturbações na função das glândulas sexuais. Além disso, chamou atenção para as implicações que os desvios das funções sexuais poderiam acarretar para as funções mentais, colocando a sexualidade no alicerce da psicologia e da psiquiatria.

Sabemos por Sérgio Carrara e Marcos Carvalho (2016, p. 17), que José de Albuquerque tratava o desejo sexual como uma necessidade orgânica primária, nesse aspecto é possível que o médico tenha tido leituras em psicanálise para basear suas afirmações, uma vez que como colocou Michel Foucault (2015, p. 121), a psicanálise veio justamente se inserir entre a lei e o desejo, para eliminar "os efeitos da interdição lá onde o seu rigor a torna patogênica". Assim, entre a repressão e a prática imoderada, a função sexual poderia ser tornada um fator de patologias psicológicas. Do ponto de vista social, argumentou que

[...] os problemas que se prendem à sexualidade, por si só, constituiriam todo um vasto programa de governo, para aqueles que, colocados na direção do país os quisessem estudar com o cuidado que merecem. Da solução dos problemas sexuais depende em grande parte o destino das sociedades e, mais do que isso, a sua própria estabilidade futura, porque envolve em si o problema da família, o problema da prole, o problema da geração de amanhã ( $A$ União, 09 nov. 1933).

Temos aí que as questões concernentes à função sexual tinham não apenas relevância biológica no nível individual, mas o reconhecimento dessas questões engendraria uma escala global ao nível da sociedade. Pois que, para José de Albuquerque, dos problemas sexuais dependeriam os destinos de uma coletividade. Estamos falando da relação de um corpo individual com a sua espécie. As questões sexuais se revelavam como uma ponte para a estabilidade futura, pois envolviam o problema da família, da prole, em suma, das próximas gerações. O sexo individual se inseria no sexo da sociedade.

Revelando o papel que a sexualidade concernia aos governos, entendemos que para o discurso do médico, o sexo de um lado pertencia as vigilâncias e controles constantes ao nível individual, no que se refere a exata noção em relação as funções sexuais de um indivíduo, por outro pertencia à regulação das populações, que visavam tomar todo o corpo social. Assim, como bem observou Michel Foucault (2015, p. 137): “O sexo é acesso, ao mesmo tempo, à vida do corpo e à vida da espécie".

Para José de Albuquerque, vencer a barreira da imoralidade que revestia a sexualidade no imaginário do povo brasileiro seria a pedra angular, condição sine que non para que o cenário estivesse adequado para tratar das questões de educação sexual. Era preciso preparar o terreno para quando chegasse a hora da educação sexual. Este seria um problema mister a ser tratado, uma vez que segundo o discurso do médico, as funções sexuais de um indivíduo não diziam respeito somente a ele, mas a toda a sociedade, pois compreendia o sexo como uma função orgânica cujo objetivo era a conservação da espécie. Para tanto, urgia não somente esclarecer a população a respeito das doenças orgânicas do sexo, isto é, próprias da função sexual, mas educar sexualmente para a prevenção contra um terrível mal que se abastava sobre a população brasileira, ameaçando 
tanto quanto, ou talvez mais, a "estabilidade futura" da "geração de amanhã": as doenças venéreas.

\section{A educação sexual e o seu papel no âmbito da luta antivenérea no Brasil}

Para Sérgio Carrara (1996) que estudou o problema da sífilis e a trajetória da luta antivenérea no Brasil entre o final do século XIX e meados da década de 1940, no campo mais amplo da medicina, a década de 1930 vai marcar o surgimento de novos discursos especializados sobre a sífilis, para além do escopo da investigação dos sifilógrafos, deslocando-a em relação à dermatologia. Carrara (1996) percebeu que esse deslocamento coincidiu historicamente com a extinção da Inspetoria de Profilaxia da Lepra e das Doenças Venéreas ${ }^{3}$. Até então, todas as propostas de intervenção social sobre as doenças venéreas eram gestadas no interior da comunidade de dermatologistas e sifilógrafos. Assim, ocorreu o surgimento de outras publicações diretamente voltadas para a sífilis, porém, com uma tendência maior a incluí-la no rol das demais doenças venéreas, ou, como foi o caso de José de Albuquerque e o seu Círculo Brasileiro de Educação Sexual, colocar a sífilis entre os demais problemas de ordem sexual (CARRARA, 1996, p. 96-98).

O contexto da década de 1930 foi marcado por uma tendência de dissolver o estudo sobre a sífilis e doenças venéreas "no âmbito mais amplo de uma reflexão sexológica" (CARRARA, 1996, p. 98). O grande objetivo de José de Albuquerque e do CBES, bem como dos periódicos por ele mantidos, como o Jornal de Andrologia e o Boletim de Educaşão Sexual, era a disseminação da educação sexual e antivenérea no país. Conforme Carrara e Carvalho (2016, p. 17), "No âmbito mais específico da luta antivenérea, José de Albuquerque concordava com os inúmeros médicos que, também naquele momento, consideravam [...] a concentração dos esforços na chamada cura profilática dos doentes um erro". O médico considerava que apesar do relevante trabalho prestado pelos dispensários antivenéreos na assistência individual do enfermo, promovendo um benefício social ao eliminar os portadores de germes, esta era, porém, uma medida muito frágil, pois os doentes praticamente nunca realizavam o tratamento de maneira conveniente e os médicos tinham, o mais das vezes, que ir à procura do doente e persuadi-lo a fazer o tratamento profilático (CARRARA; CARVALHO, 2016).

O dr. José de Albuquerque enfatizou a eficácia da propaganda de educação sexual, como principais armas no combate à sífilis e doenças venéreas. Somente uma propaganda massiva e bem orientada poderia surtir efeito no combate a essas enfermidades. Por isso mesmo, conforme já assinalamos anteriormente, o médico havia deslocado o problema das doenças venéreas para a própria sexualidade. Educando sexualmente os indivíduos, o médico defendia que seria criada uma mentalidade, fomentados hábitos saudáveis que conformariam corpos para a higiene sexual, prevenindo não só doenças orgânicas, mas doenças contagiosas. Dentre os instintos orgânicos, naturais do ser humano, o sexólogo afirmava que o instinto sexual era o que falava mais alto de todos, sendo necessário saber “[...] como conduzi-lo, para não ser levado a encara-lo num sentido daquele que lhe é destinado" (A União, 19 jan. 1935).

Encarado como um impulso natural, dedicado a preservação da espécie, o sexo não deveria

\footnotetext{
${ }^{3}$ Criada no Rio de Janeiro, em 1920, a Inspetoria de Profilaxia da Lepra e Doenças Venéreas, que também ficaria encarregada da profilaxia do câncer, tinha como grande objetivo o combate à sífilis. A proposta de erradicação da sífilis no Brasil, isto é, os princípios norteadores de uma "luta antivenérea", foi elaborada pelo sanitarista Eduardo Rabello e seu grupo, sendo explicitada no regulamento do DNSP e surgiu em meio ao debate sobre a regulamentação ou a abolição da prostituição, que provocaram discussões acaloradas que atravessaram o século XIX e adentraram o século XX (CARRARA, 1996).
} 
ser desviado, deturpado por qualquer conotação "imoral”. A única forma de fazê-lo seria ter uma orientação sexual adequada, pois o influxo sexual, seria representado por “[...] provocações, insinuações e solicitações de indivíduos de um sexo sobre outro sexo, que requerem do indivíduo a quem são dirigidas, uma educação sexual conveniente" ( $A$ União, 19 jan. 1935). Para José de Albuquerque:

Uma das principais características do homem dos nossos dias, é ver tudo através de um vêo de carne; assim é que em cada ato, em cada palavra e cada gesto de uma mulher, que encontra em seu caminho, descobre algo de provocador, algo convidativo ao ato sexual, pelo que se precipitam sem maior reflexão ás mais extravagantes aventuras, que no máu sentido chamam de "amorosas" (A União, 09 mar. 1934).

O médico reprovava o comportamento masculino que em tudo sexualizava - e ainda sexualiza - o corpo feminino, reduzindo a mulher à um mero objeto sexual. Vivendo em um estado de "erotização permanente", os homens se transformariam em um tipo que o médico classificava sob a rubrica de "patológicos". Vendo tudo através do "véo da carne", é possível supor que para o médico um estado sexual patológico poderia despertar os mais diversos tipos de violência sexual, além do adultério.

Ricardo dos Santos Batista (2014), em seu estudo sobre sífilis, prostituição e convenções de gênero, observou que a propagação da sífilis contribuiu no sentido de reforçar a mobilização do discurso médico voltado para conhecer a vida sexual principalmente das meretrizes. Outra consideração importante suscitada pelo autor, diz respeito a construção de convenções de gênero e sexualidade a partir dos discursos médicos sobre a sífilis e as doenças venéreas. Segundo Batista (2014, p. 68) "As convenções de gênero e sexualidade impactavam de forma diferente homens e mulheres, devendo o masculino ser representado pela virilidade, pela permissividade, pela ocupação do espaço urbano, enquanto o feminino pelo recato, pela submissão e afazeres domésticos". Assim, a sífilis em sua relação com a prostituição e a sociedade girava principalmente em torno da preservação da família.

Para José de Albuquerque, a educação sexual funcionaria como um elemento para conduzir o indivíduo a desenvolver suas funções sexuais e evitar "[...] cumprir de forma desordenada, as leis do sexo, quando não transgredi-las mesmo" (A União, 09 mar. 1934). Como Sérgio Carrara (1996) chamou a atenção, segundo José de Albuquerque a intensa educação sexual serviria para sanar a desarmonia sexual e resolver os crimes sexuais. Por conta dessas insinuações e provocações dos indivíduos de ambos os sexos, era importante ter clareza a respeito da "tortuosa" vida sexual.

José de Albuquerque considerava um crime o silêncio sexual. Os pais que por vergonha ou pudor negligenciavam tratar com seus filhos sobre as questões sexuais estariam cometendo "[...] delito, e delito grave", pois urgia zelar pela preservação da família e cabia a eles e a mais ninguém “[...] zelar pela felicidade futura dos seres de cuja vida foram autores" (A União, 13 abr. 1934). Para o médico:

Não seria digno ser chamado de PAI pelo seu filho, o homem que por pudor, deixa-lo ingressar ás cegas na estrada tortuosa da vida sexual, quando em suas mãos estavam os meios de afastar do seu percurso as pedras, em que o filho porventura pudesse tropeçar, cahir, e queda em queda, ser levado aos abismos mais profundos (A União, 13 abr. 1934).

Os abismos mais profundos a que o médico se refere, eram uma metáfora para as doenças venéreas. Tratava-se de dar, como disse Susan Sontag (2007), a uma coisa o nome de outra. Um 
exercício tão antigo como a própria linguagem científica. O papel da educação sexual era fazer com que os pais compreendessem o importante papel que lhes cabia na educação sexual de seus filhos, para não se verem no futuro "[...] sofrendo a dôr moral de um crime que praticaram por ignorância e inconscientemente" (A União, 13 abr. 1934), pois que:

\begin{abstract}
Não é pequeno o numero de pais, que ao verem os filhos acometidos de doenças venéreas, teem sua consciência despertada e então sentem-se culpados, considerando-se co-autores da desgraça de seus filhos. Só então é que verificam o erro em que incidiram, de ocultar-lhes aquilo que deveriam ter ensinado; arrependem-se, mas, o arrependimento em nada modifica o estado mórbido do filho ( $A$ União, 13 abr. 1934).
\end{abstract}

A sífilis, em seu papel de flagelo social, ao menos não era misteriosa. Como bem esclareceu Susan Sontag (2007), ao falar das metáforas dessa doença, contrair a sífilis era uma consequência em geral de manter relações sexuais com quem tinha a doença. Apelando para o caráter de culpa, José de Albuquerque criticava o pudor e a ignorância dos pais em matéria de educação sexual, que só depois de "[...] verificarem o erro em que incidiram, de ocultar aquilo que thes deveriam ter ensinado" (A União, 13 abr. 1934) é que se arrependiam. Mas o arrependimento não modificaria o estado mórbido do filho.

Sem a devida orientação a respeito dessas questões, a mocidade era considerada pelo médico uma vítima imprevidente da dissimulação da sífilis e doenças venéreas. Não orientando de maneira devida os filhos, os pais eram corresponsáveis pelo estado mórbido de sua prole. Com o olhar de Olivier Faure (2009, p. 51), somos chamados a perceber como no discurso médico enfatizou que os "[...] fatores mórbidos mais sondados e mais invocados pertencem à esfera pessoal e fazem apelo à responsabilidade individual que se tornou central na sociedade liberal". Por ignorância, a responsabilidade do contágio era do doente, mas também do pai, para quem os filhos “[...] olharão do íntimo de sua consciência como responsável pelas doenças cujas consequências carregam para a vida inteira" (A União, 13 abr. 1934).

Em outro artigo do serviço especial do Círulo Brasileiro de Educação Sexual, só que dessa vez publicado no semanário Estado Novo de Cajazeiras, o médico José de Albuquerque frisou que os problemas sexuais deveriam merecer a mais detida atenção, justamente porque deles dependiam o problema da herança. Segundo o sexólogo, não haveria nada "[...] de mais proveitoso em matéria de defesa sanitária das proles” (Estado Novo, 19 abr. 1941), que seria a higiene da procriação.

O tema da hereditariedade mórbida, isto é, a transmissão de caracteres mórbidos adquiridos para a prole, foi tema alvo de investigações e muitas elaborações discursivas por parte da medicina da passagem do século XIX e nas primeiras décadas do século XX. A sífilis, sobretudo, mobilizou o imaginário médico, que elaborou a teoria da "heredo-sífilis", provocando um pavor com relação ao medo da transmissão venérea pela herança. Afirmava-se que a sífilis de um ancestral poderia se inscrever no tempo e contaminar os seus descendentes mais longínquos (CORBIN, 1981). O mesmo pensamento pode ser identificado nas considerações feitas por José de Albuquerque:

Umas doenças se transmittem de paes a filhos, outras poupam os descendentes da primeira geração para irem aparecer nos da segunda; outras, só se transmittem quando a mãe é portadora - são as doenças ditas de herança matriarcal - outras só se transmittem aos descendentes de determinado sexo; outras criam apenas predisposição; outras não se transmittem tal qual nos paes, manifestando seus effeitos nas proles sob aspectos os mais diversos, e assim por diante (Estado Novo, 19 abr. 1941). 
Embora não cite nominalmente a sífilis e outras doenças venéreas, a referência é explícita. Conforme esclareceu Alain Corbin (1981), para o pensamento médico sobre a hereditariedade mórbida, a sífilis abrangia quase todas as patologias possíveis de ser transmitidas por herança, não apenas na primeira, mas na segunda geração e nas vindouras. Essa doença foi considerada como um princípio etiológico geral, como a origem dos mais variados aspectos mórbidos (CORBIN, 1981; CARRARA, 1996). Esse fenômeno vem acrescentar e reiterar o importante papel que caberia a educação sexual e reforçar que as funções sexuais não diziam respeito somente ao indivíduo, mas também a sociedade, uma vez que as doenças que ele portava poderiam ser transmitidas à sua prole, ou seja, por meio da reprodução humana, portanto, através da função sexual.

De acordo com Ricardo Batista (2017), os sifilíticos hereditários, eram representados como seres degenerados ou não desenvolvidas. Acreditava-se que a sífilis hereditária, implicaria não somente a interrupção do desenvolvimento físico, mas também mental da criança. Desse modo, “[...] contribuindo para a multiplicação de sujeitos integrantes de uma raça inferior” (BATISTA, 2017, p. 116).

José de Albuquerque chegou a cogitar algumas medidas que deveriam ser tomadas visando a regulação dos assuntos em torno da natureza sexual. Legislar sobre esse tema era, para o médico, de extrema atualidade. Dentre os pontos que o sexólogo tratou, no que descreveu como uma política sexual, destacamos a ênfase em medidas que visassem "instituir leis que regulassem as questões eugênicas", com o claro objetivo de "preparar proles sãs, conferem ao país gerações de homens sadios" (A União, 02 dez. 1933).

Dentre as medidas que se deveria legislar, o médico destacou leis que visassem a difusão da educação sexual “[...] para que não se deixasse o homem se entregar às cegas a vida sexual, arriscando-se à toda sorte de danos que tal ignorância ou cegueira lhe acarretam" ( $A$ União, 02 dez. 1933), ou seja, aquilo que anteriormente já chamamos a atenção no discurso do médico para os cuidados com a juventude, no sentido de dar aos jovens uma orientação e conselhos convenientes sobre educação sexual para evitar o contágio venéreo. José de Albuquerque em seu programa, era favorável ao controle de natalidade, que na época, segundo ele, era "[...] de uma necessidade sob diversos pontos de vista, justificada".

No que tange ao âmbito específico da luta antivenérea, José Albuquerque era legalmente favorável a instituição de um delito de crime venéreo, mas com restrições. Segundo dizia, deverse-ia instituir leis que regulassem "[...] o delito de contágio venéreo, não com a amplitude que a quiseram há anos instruir entre nós, o que vinha a dar um golpe de morte no "segredo médico", mas com a responsabilização dos contaminadores, devidamente provado por processos regulares" (A União, 02 dez. 1933). Conforme esclareceram Carrara e Carvalho (2016, p. 19), o médico não parecia acreditar que tal medida fosse exequível, pois dado o caráter estigmatizante da sífilis, se o contagiado denunciasse o "contagiador", estaria ele divulgando publicamente seu estado mórbido de doente venéreo. Contudo, o sexólogo apoiava tal medida, porque ela poderia gerar receio entre os possíveis contaminadores e, sobretudo, porque ela seria optativa (CARRARA; CARVALHO, 2016).

Era favorável ainda a uma maior difusão de postos de profilaxia antivenérea, mas em moldes diferentes dos que existiriam até então, bem como de leis que de certa forma controlassem o exercício do meretrício, mas “[...] sem que se veja nisso um incentivo à prostituição" (A União, 02 dez. 1933). No que se refere aos postos de profilaxia antivenérea, é mais uma vez o diálogo com Carrara e Carvalho (2016) que vem lançar luz sobre essa questão. A ideia de Albuquerque era fazer com que os preventórios e postos antivenéreos estivessem mais próximos dos doentes, pois 
segundo ele, muitos doentes teriam vergonha de serem vistos procurando o serviço ou estariam muito distantes dele.

Segundo Maria Stephanou (2000), que estudou a escolarização dos saberes médicos na primeira metade do século XX, mostrou que na formulação de alguns médicos, como é o caso aqui estudado do dr. José de Albuquerque, “[...] a educação sexual era associada às discussões eugênicas e em outros à profilaxia das doenças venéreas" (STEPHANOU, 2000, p. 8). Nas formulações do sexólogo carioca, temos que a educação sexual estava atrelada tanto as discussões eugênicas, como fica explícito no discurso publicado através de artigos em periódicos que faziam parte do circuito de divulgação do CBES, como também à profilaxia das doenças venéreas. Para José de Albuquerque, a educação sexual, massiva e bem dirigida, era uma arma profilática eficiente contra as doenças venéreas.

Como visto, a sífilis e outras doenças venéreas eram um risco não apenas individual, mas também coletivo. Por isso a educação sexual, afirmava-se enquanto um discurso que "[...] defendia a disciplina individual assentada em razões que partiam do próprio desejo do sujeito, ou seja, preservar sua saúde e sua vida" (STEPHANOU, 2000, p. 8).

Em seu estudo sobre a relação entre médicos e educadores com o discurso eugênico, Vera Regina Beltrão Marques (1994, p. 78), cuja análise vem corroborar com a nossa argumentação, afirmou que as "[...] doenças sexualmente transmissíveis constituíam outro item de apelos eugênicos acerca da sexualidade responsável, daquela que se faz disciplinadamente". Dessa forma, vamos ter a compreensão que os discursos elaborados sobre a educação sexual vão encontrar " [...] nas doenças sexualmente transmissíveis um canal efetivo de acesso à vida do corpo e também da espécie (MARQUES, 1994, p. 78).

O nosso argumento é o de que a educação sexual se constituiu como um dispositivo biopolítico, uma vez que, sujeitando corpos individuais a um saber médico sobre o sexo, vinculado determinações da eugenia, promovia o controle da população. O elemento biológico se revestiu de poder político. A vida e seus mecanismos entram no domínio de cálculos explícitos. Dever-se-ia investir no corpo, na saúde, nas condições de vida e de existência, de modo a retirar das populações o maior acúmulo de forças produtivas possível. Educando os indivíduos desde cedo, o homem ocidental "[...] aprende pouco a pouco, o que é ser uma espécie viva num mundo vivo, ter um corpo, condições de existência, probabilidade de vida, saúde individual e coletiva, forças que se podem modificar, e um espaço em que se pode reparti-las de modo ótimo" (FOUCAULT, 2015, p. 154).

Nesse ponto, somos levados a analisar o que as formulações discursivas do dr. José de Albuquerque implicavam para as crianças e jovens, pois compreendemos que no discurso desse médico, houve a preocupação com as condições de existência e de saúde a nível individual e coletivo com relação aos problemas sexuais desde a mais tenra idade. Sendo assim, formulamos alguns questionamentos que lançam luz sobre essa problemática, afinal, como deveria se dar a educação sexual? Como o médico, que outorgou para si o direito sobre o sexo, concebia essa educação sexual? Qual o papel delegado aos pais, e também aos professores, quanto a educação sexual das crianças? É o que discutiremos a partir de agora.

\section{"Com naturalidade, sem fantasias": o discurso médico-pedagógico de educação sexual para crianças e jovens}

Em um artigo publicado em 1933 no jornal $A$ União, período inicial e de intensa atividade 
de publicação do CBES, José de Albuquerque se dedicou a responder justamente o seguinte questionamento: como se deve conduz̧ir a educação sexual da criança? Para o médico, na infância a educação sexual deveria estar subordinada exclusivamente ao fator "oportunidade", e afirmava que a educação sexual da criança era mesmo "[...] uma questão de saber aproveitar as ocasiões" (A União, 20 out. 1933).

A educação sexual competia ser cuidadosamente ministrada por aqueles que conviviam de forma mais direta com as crianças, ou seja, os pais e professores para os meninos e as mães e professoras para as meninas. Tudo deveria acontecer sem muito exagero, na medida em que a criança fosse formulando questionamentos no que diz respeito a assuntos sexuais. Para o médico era de extrema importância que tais curiosidades das crianças fossem devidamente elucidadas, do contrário, “[...] si não for decididamente elucidado, tornar-se-á recalcado, segundo a concepção freudiana sob muitos aspectos justa e verdadeira" (A União, 20 out. 1933).

Os pais não deveriam jamais, ressaltava o médico, repreender os filhos, proibindo-os de tratar de tais assuntos, pois isso somente alimentaria mais a curiosidade das crianças, que agora iriam buscar desvendar um outro mistério: "[...] o "porque" de seus pais o prohibirem de se referir a tais assuntos", pois desse modo, daí em diante "[...] a criança se torna presa de uma curiosidade sem limite, em relação aqueles dois enigmas, para a decifração dos quais começa a envidar todos os esforços e a empregar um sem número de artimanhas e truques" (A União, 20 out. 1933).

Se referindo ao aspecto psicológico das crianças, José de Albuquerque afirmava que era perigoso de igual modo fantasiar demasiadamente as respostas, de maneira que as explicações pudessem parecer inverossímeis. O que poderia parecer satisfazer a curiosidade da criança, na realidade, as deixaria "[...] mais confusas e curiosas as tornariam, sobretudo quando tem oportunidade de constatar, a inverdade das respostas" (A União, 20 out. 1933). Por isso, o médico aconselhava aos pais que buscassem responder as crianças de maneira genérica, metaforizando a função reprodutora humana com a função reprodutora de animais domésticos e vegetais, uma vez que esta seria "[...] a melhor maneira de satisfazer a curiosidade das crianças e não se dar lugar, a que se transforme em enigma nos cérebros infantis uma função que nada tem de imoral” (A União, 20 out. 1933).

Evitando o recalque dos desejos e curiosidades das crianças e jovens, José de Albuquerque argumentava que teria sido feita a profilaxia de uma série de "nevroses e psiconevroses, que na idade genital vão levar as manifestações ao domínio da sexualidade, concorrendo para aumentar a cifra de enfermos". O sexólogo, então, concluía que “[...] a educação sexual da criança deve ser ministrada com naturalidade, sem fantasia, em linguagem acessível aos diversos graus de mentalidade do educando" (A União, 20 out. 1933, grifos meus). Era importante não fantasiar os argumentos utilizados para educar a criança em relação ao sexo e sua sexualidade, mas deveria se buscar uma linguagem clara e direta, sobretudo, dentro do universo da criança para tornar os conhecimentos acessíveis.

Segundo os conselhos do médico dados aos pais e professores, dever-se-ia esperar o momento certo, o imperativo da oportunidade, para introduzir essa educação sexual para as crianças. Essa também era a tônica presente nos conselhos timbrados nas páginas da Revista do Ensino ${ }^{4}$, que despertava a necessidade de um cuidado especial com a educação infantil e dava conselhos especiais para os pais:

\footnotetext{
4 Periódico que circulou no estado da Paraíba durante dez anos (1932- 1942), totalizando 18 números, divididos em 15 exemplares. A Revista do Ensino foi um espaço, por excelência, criado para veicular os debates educacionais no estado da Paraíba sobre os novos modelos de ensino, as concepções de infância, espaço e tempo escolares, formação docente, etc. (LUCENA, 2015).
} 
É muito importante a ideia exata que seu filho tem com referência ao sexo. Responda-lhe franca e honestamente quando ele perguntar de onde vem as crianças, e si demonstrar qualquer curiosidade sobre o corpo humano. Si mostrar-se evasivo ou construir histórias imaginárias, ela não lhe fara mais perguntas, mas conseguirá em outro lugar a informação que deseja. Essa informação talvez lhe seja dada de um modo deturpado por outra criança ou por um pervertido. Si estiver embaraçado para explicar o processo de reprodução e corrigir idéias erroneas a esse respeito, consulte o médico da família (Revista do Ensino, jul. 1934, p. 42).

Percebemos que apesar da sexualidade ser considerada um tabu, era preciso iniciar naquele momento um intenso debate acerca do tema e contribuir para uma educação da saúde, para a circulação dos saberes médicos sobre o sexo e para a instituição de uma moral sexual. Dialogando com as ideias de Michel Foucault (2015), percebemos que a sexualidade da infância no discurso do dr. José de Albuquerque estava elaborada na ideia de um sexo que está presente anatomicamente, mas ao mesmo tempo ausente do ponto de vista fisiológico. Devido ao risco para a saúde dos futuros adultos, "a sexualização da criança foi feita sob a forma de uma campanha pela saúde da raça” (FOUCAULT, 2015, p. 158). Diante dessa preocupação, o poder-saber médico sobre o sexo e os dispositivos de sexualidade atuaram a partir da articulação de uma série de estratégias dentre elas, o que Foucault (2015) chamou de "Pedagogização do sexo da criança". Assim, o discurso da sexologia, compreendia que:

Quase todas as crianças são suscetíveis de se dedicar a uma atividade sexual; e de que tal atividade sexual sendo indevida, ao mesmo tempo "natural" e "contra a natureza", traz consigo perigos físicos e morais, coletivos e individuais; as crianças definidas como seres sexuais "liminares", ao mesmo tempo aquém e já no sexo, sobre uma perigosa linha de demarcação (FOUCAULT, 2015, p. 114).

Percebemos como o discurso do dr. José de Albuquerque se inseria na "pedagogização" do sexo da criança, que emerge no século XIX como um dispositivo da sexualidade, visando analisar, esmiuçar a atividade sexual das crianças, seja devido ao problema do onanismo ou as perversões sexuais, seja devido as patologias provocadas pela repressão ou excesso das funções sexuais. Mesmo estando ausente fisiologicamente, pois as crianças não desempenhariam atividades sexuais, o sexo estaria presente anatomicamente nas glândulas endócrinas do aparelho reprodutor, embora ainda não desenvolvidas, e por isso mesmo, alvo da preocupação médica, como o discurso do dr. José de Albuquerque revela, visto que lesada na infância, a função sexual traria consequências patológicas para o resto da vida.

Dessa forma, o discurso médico-pedagógico da sexologia, transformava os "[...] pais, os cônjuges, tornam-se, na família, os principais agentes de um dispositivo de sexualidade que no exterior se apoia nos médicos e pedagogos" (FOUCAULT, 2015, p. 120). O papel a ser cumprido pela educação sexual seria o de ensinar a função exata do sexo para as crianças, portanto, compreender biologicamente como funcionava a reprodução humana.

Quanto aos professores, a oportunidade de ensinar educação sexual para as crianças lhes seria “[...] dada por ocasião do ensino de história natural” ( $A$ União, 10 fev. 1934). De acordo com Giselle Reis (2006), a proposta do José de Albuquerque era de que a educação sexual deveria ser composta pelo ensino dos fatos da biologia, como a apresentação de estatísticas ou de quadros comparativos acerca dos problemas que circulavam em torno da educação sexual. A autora, que estudou a sexologia e a educação sexual nas décadas de 1930 a 1950 a partir da obra de José de Albuquerque, esclareceu que a finalidade da educação sexual no âmbito escolar para este médico seria a de ensinar para: 
[...] o indivíduo a "real" função da sexualidade, como ela funciona e como o indivíduo deve conduzi-la e quais são as etapas do desenvolvimento sexual do indivíduo, desde a infância até a velhice. Esclarecendo para o indivíduo as funções e o desenvolvimento da sexualidade, este gozaria de uma forma normal de suas funções, assim como todas as outras funções de outros órgãos, gozaria de um pleno desenvolvimento saudável de suas funções mentais e também estaria contribuindo para a evolução de sua espécie (REIS, 2006, p. 56).

A educação sexual das crianças era vista como uma forma de garantir o controle da reprodução, uma forma de regenerar a raça por meio da instrução adequada, educando as novas gerações desde cedo nas questões sexuais. Educar sexualmente as crianças tratava-se de uma prática educativa que visava conformar os desejos e as vontades, levar os indivíduos ao autocontrole e assim cuidarem da sua própria higiene, de si mesmos e do seu sexo. José de Albuquerque propunha, então, a educação sexual dentro da educação sanitária e considerava de extrema importância que a escola oferecesse a educação sexual para criar hábitos higiênicos e desenvolver uma moral sexual (bons hábitos e comportamentos) nos escolares. Para ele

[...], a educação sexual, deveria ocupar o lugar estritamente necessário para cumprir a sua função. Se a ela cabia o papel de ensinar ao aluno a função exata do sexo e os cuidados que se deveria ter em relação à higiene de seus órgãos genitais, não haveria a necessidade de uma cadeira específica. O indicado seria um professor que desse ao aluno uma visão de uma função natural do sexo e dos órgãos genitais, tão naturais como de todos os outros órgãos. Assim, a função sexual deveria ser encarada como "natural" e não como imoral (REIS, 2006, p. 70-71).

A educação sexual, portanto, estava inserida dentro da educação sanitária, pois buscava desenvolver desde a mais tenra idade, bons hábitos higiênicos no que concerne à moral sexual individual. O papel a ser cumprido pela educação sexual seria o de ensinar a função exata do sexo para as crianças, portanto, compreender biologicamente como funcionava a reprodução humana, os cuidados com a higienização dos órgãos sexuais. Dever-se-ia naturalizar o sexo, retirando-lhe qualquer conotação imoral ou deturpada que pudesse significar outra função que não a biológica a respeito da questão sexual.

Por fim, chamamos a atenção para o que o dr. José de Albuquerque chamou de pentálogo da educação sexual, uma série de imperativos para que pais e mestres tivessem presentes para si quando fossem tratar com as crianças e jovens de assuntos relacionados a sexualidade. O médico exortava os pais e professores para:

a) - que não procurem envolver num halo de mistério, os problemas da vida sexual, ao cogitar deles com seus filhos ou seus discípulos, mas sim que respondam criteriosa e verticalmente, as questões que sobre a sexualidade lhes forem pelos mesmos formuladas;

b) - que não concorram para criar na mentalidade infantil, o falso conceito, de que a função sexual é uma função de prazer, como tal, dela devendo se abster, como meio de obtenção de graças sobrenaturais, mas sim, que demonstrem ser esta função substancialmente igual as demais e tão necessária como qualquer outra, á conservação da saúde e ao equilíbrio geral do organismo;

c) - que não permitam que seus filhos ou discípulos, associem ou continuem a associar, o conceito de imoralidade ao de sexualidade, mostrando-lhes que nenhuma função é imoral, quando orientada de acordo com o fim fisiológico a que se destina e que todas podem ser imoralizadas, uma vez que se desviem de sua verdadeira finalidade;

d) - que não pratiquem o crime de deixar ingressar na puberdade, criaturas completamente desconhecedoras dos mil e um perigos que as esperam, para somente as ensinar, depois de precipitadas muita vez na voragem do abismo, mas sim, que se ministre em tempo oportuno 
os conhecimentos indispensáveis de fisiologia e higiene sexuais, que possam influir no sentido de melhor orienta-las na conduta de sua vida sexual;

e) - que, finalmente, não tragam seus filhos e discípulos, acorrentados ao peso destes terríveis grilhões que o empirismo e a rotina veem impondo á humanidade sob o nome de "Moral", mas sim, que iluminem o espírito da juventude com um raio desse sol ardente e vivificador que é a ciência, apontando-lhes as estradas largas, retas e sem atalhos da verdadeira Moral Sexual, que é a que se funda nos postulados da Ciência (A União, 10 fev. 1934).

O primeiro ponto, remete a naturalidade com que se deveria tratar o tema de sexo, quando surgissem perguntas. Respostas criteriosas e verticais. Sem fantasias ou explicações mirabolantes. De acordo com o médico, os pais e professores falavam de um lugar de autoridade e, portanto, deveriam se manifestarem como tal. O segundo, discorre sobre a natureza do desejo sexual, criticando a abstinência sustentada por valores metafísicos para obter "graças sobrenaturais", o médico reafirma a função sexual como necessária ao equilíbrio do organismo e da qual dependeria a saúde do corpo, negar a natureza do desejo sexual só acarretaria desvios funcionais ou psicoses.

O terceiro ponto do qual fala o pentálogo, remete à máxima do pensamento de José de Albuquerque, de que a sexualidade não era imoralidade, enfatizando que todas funções do organismo poderiam ser imoralizadas caso fossem desviadas da sua "verdadeira" finalidade. A função sexual, portanto, deveria ser orientada de acordo com a necessidade fisiológica, qual seja, a conservação da espécie.

Em quarto lugar, o pentálogo retoma e sistematiza a ideia do "crime do silêncio" a respeito da responsabilidade de pais e professores quanto a instrução adequada dos filhos a respeito da educação sexual, ao deixar os jovens ingressarem às cegas na vida sexual, sem ter qualquer orientação que os pudessem auxiliar quanto a sua fisiologia e higiene sexual, bem como se proteger das doenças venéreas que estariam à espreita dos jovens incautos. Por fim, o médico traz o evangelho científico metaforizado como sol que ilumina com seu conhecimento e liberta dos grilhões da ignorância que a moral acorrenta. Retirava a moral de fundo religioso e estabelecia um novo referencial a partir da ciência.

Que a educação sexual passou a ser contemplada nas páginas da imprensa nacional e paraibana, sobretudo na década de 1930, é fato. Isso se deu, especialmente, devido a proliferação das doenças venéreas que acometia famílias inteiras, gestando assim outros problemas: a transmissão para esposas e filhos. Nesse sentido, os médicos passaram a debater a importância de publicar na imprensa em circulação, as devidas informações e orientações para combater não apenas as visitas aos prostíbulos, mas de divulgar os cuidados necessários ao corpo diante das doenças do sexo. A sexualidade passou a ser pauta em voga. Seus recônditos mais íntimos ganharam visibilidade. $\mathrm{O}$ corpo passou a ser desnudado no sentido de revelar os segredos mais escusos. A doença denunciava os vícios do sexo e as visitas aos espaços da prostituição.

\section{Considerações finais}

Percebemos que ocorreu um investimento discursivo na educação sexual como parte integrante de uma biopolítica, como uma prática educativa que visava promover a vida através da proliferação de publicações contendo discursos médico-pedagógicos remetidas pelo Círculo Brasileiro de Educação Sexual sob a chefia do dr. José de Albuquerque, sobretudo, no periódico A União, Órgão Oficial do Estado da Paraíba. Não é possível afirmar sobre os termos de apropriação dessa política para com a população paraibana, pois as fontes em análise não nos permitem inferir isso. 
Mas, é notório que a terceira década do vigésimo século, foi de fundamental importância para fazer circular, ao menos na imprensa, novas formas de pensar a educação sexual, que se pretendia, naquele momento, se libertar da malha asfixiante da ignorância, da falta de conhecimento científico.

O sexo e as doenças do sexo - contagiosas ou fisiológicas - estiveram na ordem do dia naquele momento histórico, marcado profundamente pelas discussões de temas eugenistas. Os debates em torno da educação sexual tiveram grande repercussão no cenário brasileiro a partir de 1933 com a fundação do Círculo Brasileiro de Educação Sexual. A quantidade de publicações na imprensa, dá um sinal de como esse assunto foi pauta presente nas discussões em torno da saúde e sua interface com a educação, visando formar gerações de homens e mulheres saudáveis a partir de uma prática sexual considerada higiênica. Como o próprio médico declarou em um dos seus artigos, a década de 1930 parece ter sido mesmo a "hora da educação sexual".

\section{Fontes}

\section{Arquivo do Jornal “A União”}

A UNIÃO. João Pessoa: Imprensa Oficial, ano 42, n. 1, 05 jan. 1935, p. 3.

A UNIÃO. João Pessoa: Imprensa Oficial, ano 41, n. 211, 20 set. 1933, p. 6.

A UNIÃO. João Pessoa: Imprensa Oficial, ano 41, n. 229, 11 out. 1933, p. 5.

A UNIÃO. João Pessoa: Imprensa Oficial, ano 41, n. 235, 20 out. 1933, p. 8.

A UNIÃO. João Pessoa: Imprensa Oficial, ano 42, n. 238, 24 out. 1934, p. 8.

A UNIÃO. João Pessoa: Imprensa Oficial, ano 41, n. 250, 09 nov. 1933, p. 3.

A UNIÃO. João Pessoa: Imprensa Oficial, ano 41, n. 269, 02 dez, 1933, p. 16.

A UNIÃO. João Pessoa: Imprensa Oficial, ano 41, n. 10, 14 jan. 1934, p. 15.

A UNIÃO. João Pessoa: Imprensa Oficial, ano 42, n. 16, 19 jan. 1935, p.1.

A UNIÃO. João Pessoa: Imprensa Oficial, ano 42, n. 33, 10 fev. 1933, p. 3.

A UNIÃO. João Pessoa: Imprensa Oficial, ano 42, n. 65, 23 mar. 1934, p. 5.

A UNIÃO. João Pessoa: Imprensa Oficial, ano 42, n. 81, 13 abr. 1934, p. 12.

\section{Arquivo Pessoal de José Antônio de Albuquerque}

ESTADO NOVO. Cajazeiras. Ano 2, n. 86, 19 abr. 1934, p. 2.

\section{Referências}

ARAÚJO, Fátima. Paraíba, imprensa e vida. João Pessoa: A União, 1983.

BATISTA, Ricardo dos Santos. Sifilis e a reforma da saúde na Babia. EDUNEB, 2017.

. Mulheres livres: uma história sobre prostituição, sífilis, convenções de gênero e sexualidade. EDUFBA, 2014.

CARRARA, Sérgio. Tributo a Vênus: a luta contra a sífilis no Brasil, da passagem do século aos anos 40. Rio de Janeiro: Editora FIOCRUZ, 1996.

CARRARA, Sérgio; CARVALHO, Marcos. (Orgs.). Meu encontro com os outros: memórias de José de Albuquerque, pioneiro da sexologia no Brasil. Rio de Janeiro: Editora FIOCRUZ, 2016.

CORBIN, Alain. L'hérédosyphilis ou l'impossible rédemption. Contribution à l'histoire de 
l'hérédité morbide. In: Romantisme, 1981, n. 31. Sangs. p. 131-150.

FAURE, Olivier. O olhar dos médicos. In: CORBIN, Alain. COURTINE, Jean-Jacques. VIGARELLO, Georges. História do Corpo 2: Da Revolução à Grande Guerra. 3 ed. Petrópolis: Vozes, 2009.

FOUCAULT, Michel. A ordem do discurso: aula inaugural no Collège de France, pronunciada em 2 de dezembro de 1970. 22 ed. São Paulo: Edições Loyola, 2012.

História da sexualidade 1: a vontade de saber. 2 ed. São Paulo: Paz e Terra, 2015.

LUCA, Tânia Regina de. "História dos, nos e por meio dos periódicos". In: PINSKY, Carla Bassanezi. (Org.). Fontes Históricas. 2 ed. 1 reimp. São Paulo: Contexto, 2008.

LUCENA, Meryglaucia Silva Azevedo. A creança é uma planta mimosa e gentil, frágil e encantadora: um estudo sobre a Revista do Ensino na Paraíba (1932-1942). 2016. Dissertação (Mestrado em Educação). Universidade Federal da Paraíba, João Pessoa.

MARQUES, Vera Regina Beltrão. A medicalização da raça: médicos, educadores e discurso eugênico. Campinas: UNICAMP, 1994.

MARTINS, Ana Luiza; LUCA, Tânia Regina de (orgs.). História da Imprensa no Brasil. São Paulo: Contexto, 2008.

REIS, Giselle Volpato dos. Sexologia e educação sexual no Brasil nas décadas de 1920-1950: um estudo sobre a obra de José de Albuquerque. 2006. Dissertação (Mestrado em Educação Escolar), Universidade Estadual Paulista, Araraquara.

SONTAG, Susan. Doença como metáfora. Aids e suas metáforas. São Paulo: Companhia das Letras, 2007.

SOUZA, Antônio José de. Cajazeiras nas crônicas de um mestre escola. João Pessoa: Editora Universitária/UFPB, 1981.

STEPHANOU, Maria. Saúde pela educação. Escolarização de saberes médicos na primeira metade do século XX. In: I Congresso Brasileiro de História da Educação, 2000, Rio de Janeiro, RJ. I Congresso Brasileiro de História da Educação. Programas e resumos dos trabalhos. Rio de Janeiro, RJ: Sociedade Brasileira de História da Educação, 2000. p. 327-328.

Artigo recebido em: 30/10/2019

Artigo aceito em: 16/01/2020 